\title{
The safety problems met by powered two-wheelers in urban traffic
}

\author{
P. Van Elslande, J.-Y. Fournier \& C. Parraud \\ The French Institute of Science and Technology for Transport, \\ Spatial Planning, Development and Networks (IFSTTAR), France
}

\begin{abstract}
An important growth in motorcycle traffic has occurred during the last decades in most parts of the world, the result of which being that powered two-wheelers (PTWs) have gradually become a true mobility tool that attract an increasingly vast and varied population. But a side effect of such an evolution refers to road safety. As a matter of fact, most epidemiological studies show the overall excess risk facing PTW in the traffic system, this risk coming notably from the extreme vulnerability of PTW riders in case of a crash and relying on some specific accident patterns. Faced with this negative aspect of riding a motorcycle or a scooter, it is essential to thoroughly understand the risks that riders meet when moving in traffic and more specifically in the urban environment where they particularly develop. The present paper has the purpose of identifying the production processes that characterise PTW traffic crashes occurring in town in comparison with those produced in the countryside. The data relies on a detailed analysis of a sample of 1000 accident police records. The results put emphasis on the difficulties confronting PTW users when on the road or in the street and to analyse the repercussions of these difficulties in terms of critical situations that are met by riders. A better knowledge of the specificities and the mechanisms of PTW involvement in injury traffic accidents is viewed as offering a potential improvement in their safety through adapted urban road development.
\end{abstract}

Keywords: motorcycling, traffic safety, urban environment, human error, accident configurations. 


\section{Introduction}

The city is a complex system which integrates multiple practices of mobility. By the profusion of the interactions which it generates, the urban area constitutes a melting pot where numerous dysfunctions concentrate, as shown by the number of traffic accidents which occur there. The works in environmental psychology [1] brought the conception that human behaviour is as much determined by the physical characteristics of the context of the activity as by the purposes of the operator [2]. Accordingly, the road environment plays a crucial role on driving behaviour, and the development of the layout, everywhere present in the city, constitutes an important lever to promote traffic safety.

Traffic safety results from the interweaving of numerous factors which put in typical different sets of more or less visible actors with regard to the levels of analysis of the dysfunctions. The end-users of the public road network constitute the direct actors, in charge of the micro-control of the traffic (drivers, riders, pedestrians, etc.). But this use joins in an overall context which is under the responsibility of the designers, the manufacturers and the administrators who are involved in the macro-regulation of this system [3]. The 'accidents of the city' are thus analysed here under the angle of this double determination of the phenomena of insecurity, searching to put forward not only the drivers' errors and other failures, but also the upstream factors originating them.

A previous study [4] was aimed at identifying the specific characteristics of passenger car crashes occurred in urban environments, allowing to better understand their mechanisms and specificities in comparison to crashes occurring in the open countryside. Face to the increase traffic of PTWs, notably in town, the same question is presently addressed to the specificity of crash patterns for this kind of vehicles. More precisely, the object of the present work is the detailed analysis of motorized two-wheelers accidents occurred in urban area, for an improvement of the knowledge on their genesis, their determiners and specificities, from the point of view of the difficulties encountered by the drivers as revealed by accident data. The knowledge stemming from such an analysis will be considered as essential for a better adaptation of the urban planning to the road users' capacities and limits.

But first, two questions must be further considered when dealing with motorcycling, the first concerning the role of PTWs within the transport system, the second refereeing to the drawbacks linked to the use of this means of mobility in term of traffic safety.

\subsection{The role of powered two-wheelers within the transport system}

The use of PTWs can present a number of advantages both at an individual and a societal level. Thanks to their capacity to overtake vehicles, allowing riders to get through most traffic jams, PTWs constitutes an efficient and flexible transport mode with the potential to travel relatively quickly and to have reliable travel times. PTW can also be a good compromise to face in inner-city parking 
problems. At a societal level, PTWs also provide a number of benefits as they respond to several concerns such as the optimisation of the usage of road space and environmental benefits in terms of pollution [5].

It was estimated that there were 313 million powered two-wheelers in operation in the world, with more than three quarters of the PTW fleet in Asia [6]. In large cities, the growing share of PTWs in the motorized fleet is much more marked. In most countries, over the past decade (2001-2010), the motorcycle fleet grew much more rapidly than the passenger car fleet. And it must be considered that this growth is likely to accelerate as the world population increases and more people recognise the potential economic, mobility and environmental benefits of PTWs. But such a development must not be accompanied by a growth in crashes, injuries and fatalities involving PTWs. The fact is that the potential benefits of PTWs regarding mobility are currently heavily mixed with an overly high societal cost regarding safety. It is essential to study these safety issues both in terms of their aetiology and in terms of solutions for promoting powered two-wheelers as a viable transport alternative to traffic congestion.

\subsection{An excessive risk}

PTWs are an integral part of the traffic system but at the same time constitute a specific component that deviates somewhat from passenger car standards and needs to be better accommodated and assimilated in the system [7]. Whereas there has been substantial progress in most countries in improving road safety and reducing road mortalities, PTW riders have not benefited at the same pace as car occupants from safety improvements over the last decade. The result is that, regardless of the countries concerned, PTW users are confronted with an excessive risk on the road, which has been qualified as 'unfair' by Elvik [8] insofar as for the same number of kilometres driven they have a much higher risk of being killed or severely injured than car occupants.

The level of risk underlying motorcycling is influenced by many factors, not only in terms of secondary safety (protection) but also in terms of primary safety (prevention). A first general factor of accident proneness is the intrinsic difficulty to ride a PTW, due to the necessity to control the balance, its lower friction capacity and its greater sensibility to environmental perturbations (wind, gravel, any change in road surface, etc.) which may destabilize the vehicle. Another influential risk is the domination of cars and larger vehicles in traffic, and the fact that the traffic system has mainly been designed for these vehicles. As a consequence, the traffic system now requires an adaptation towards the integration of the growing volume of powered two-wheelers. In that purpose, it is necessary to thoroughly study the difficulties met by the riders and the other road users facing them, as they are expressed notably in traffic accidents. And this is particularly relevant in urban environment where PTW traffic is a growing issue. The fact is that $42 \%$ of the motorcycle rider fatalities and $58 \%$ of the moped riders fatalities in Europe in 2008 occurred inside urban areas. These proportions are considerably larger than for car occupants (23\%) [9]. 


\section{Method}

\subsection{Data and models}

The research work is based on a detailed analysis of a representative sampling of 1000 accidents police reports involving at least one powered two-wheeler. $78 \%$ of them occurred on an urban area, $22 \%$ in the countryside. The analysis was conducted in a way to extracting systematic information on: the typical accident configurations, the combinations of human-vehicle-environment factors involved and the consecutive drivers' errors and other human failures involved in the accident process.

This sample was built from a random sampling of accident cases gathered at the national level by IFSTTAR Institute (France) for research purposes, this sampling being representative of the injury accidents reported in France by the Police services. The accident reports include statements by the persons involved and the witnesses, a map of the accident site with the situation of the collision point and position of the vehicles after the crash, medical data on the injuries, sometimes photographs of the site, etc.

The analysis made use of both an accident phase model [10] allowing the segmentation of the accident process in a systematic way; and a human failure model (HFF) allowing the classification of the driving functional failures (i.e. human errors and capacity exceeding) found in traffic accident and of the factors of these failures [11]. The HFF model distinguishes five major functional categories within which can be identified the incapacity of a function (perceptive, diagnostic, prognostic, decision, motor) to overcome a difficulty encountered by the driver. A sixth heading deals more with a problem of general aptitude to drive than the specific capacity to handle a difficulty: these 'generalized failures' correspond to an alteration to the entire functional chain (i.e. on the perceptive, cognitive and psychomotor levels) making the driver unable to manage the slightest difficulty encountered on his route (e.g. falling asleep). These different categories of failures are delineated in 20 types, which will be further detailed in the results part, as will also be detailed the different factors of these human failures and the level of involvement of the different drivers concerned.

\subsection{Coding reliability}

In order to check the reproducibility of the coding method used, an inter-rate reliability was tested in a previous study applying the same method on another sample of crash files [12]. The analysis of the reliability rate was performed on the basis of the comparison between the coding in parallel of 100 crash reports by two teams of coders. The proportion of inter-expert agreement was measured for the variables 'categories of failures' and the 'types of failures' identified for each driver studied, and also for the factors of these driving failures. A Cohen's Kappa coefficient was measured for each observed proportion of agreement, and the scale proposed by Landis and Koch [13] was used to test the validity of the 
results. These results gave a rate of agreement above $80 \%$ for the variables 'categories of failures' and 'types of failures' (Kappa coefficient between 0.73 and 0.86 ), which correspond to a 'good' up to 'excellent' agreement according to the Landis and Koch scale. Regarding the variables 'factors of failures' (from 1 to five items identified, depending on the case), the agreement rate was $94 \%$ for the first item and $70.5 \%$ for the second one with Kappa values of 0.94 and 0.67 corresponding to agreements considered 'excellent' and 'good'. The agreement then tends to decrease for the following explanatory elements, which can be explained by the fact that they correspond to more secondary factors as regard to the accident process production.

\section{Results}

The present section will deliver the essential results by first comparing urban versus countryside crashes, and secondly by focusing on the urban ones with the view to investigate the eventual differences characterizing three main categories of PTWs: 1) Mopeds with an engine displacement less than $50 \mathrm{~cm}^{3}$, 2) Light motorcycles with a displacement less than $125 \mathrm{~cm}^{3}$, and 3) Motorcycles with a displacement above $125 \mathrm{~cm}^{3}$.

\subsection{Level of involvement in urban vs. countryside areas}

The variable 'level of involvement' described in this section defines the role played by each driver (i.e. motorcyclist and motorist) involved in the genesis of the accident. Close to the notion of 'responsibility', it differs nevertheless from this latter by the reference not to a legal code but to a strictly behavioural reference, with the purpose to better understand the whole accident process. The first modality, 'Primary contributing', designates the drivers who are at the origin of the conflict that ended into a crash. The second modality, 'Secondary contributing' relates to drivers who contribute to the non-resolution of the conflict generated by not trying to prevent or react in spite of alarming indications. The 'No contributing' modality includes all the drivers who have been confronted to a conflict without having the possibility to see it in advance nor to react on time.

Table 1: Riders' level of involvement for urban and countryside crashes.

\begin{tabular}{|l|l|c|}
\hline & Urban & Non-urban \\
\hline Primary contributing & $35.0 \%$ & $51.8 \% * *$ \\
\hline Secondary contributing & $56.2 \% * *$ & $36.8 \%$ \\
\hline No contributing & $8.8 \%$ & $11.4 \%$ \\
\hline Total $(\mathrm{n})$ & 794 & 228 \\
\hline$* \mathrm{p}<0.01$.
\end{tabular}




\subsection{PTW riders failures in urban vs. countryside areas}

When comparing urban and non-urban environments, a first distinction appears in the categories of human functional failures to which PTW riders are more subject along the accident generating processes. As seen on Table 2, PTW riders are significantly more subject in urban environment than in the countryside to failures at the prognosis level $(38.8 \%$ vs. $29.3 \%)$, which refers to the anticipation and prevision functions. They also show a tendency to be more prone to failures at the perception level $(27.2 \%$ vs. $22.12 \%)$. On the opposite, riders involved in an accident occurring in the countryside are showing far more deficiencies at the execution level of the driving process $(26.0 \%$ vs. $12.8 \%)$.

Table 2: Distribution of riders' failure categories for urban and countryside crashes.

\begin{tabular}{|c|c|c|}
\hline & Urban & Non-urban \\
\hline Perception & $27.2 \%$ & $22.1 \%$ \\
\hline Diagnosis & $10.0 \%$ & $8.2 \%$ \\
\hline Prognosis & $38.8 \% *$ & $29.3 \%$ \\
\hline Decision & $8.2 \%$ & $9.6 \%$ \\
\hline Execution & $12.8 \%$ & $26.0 \% * *$ \\
\hline Generalized & $3.0 \%$ & $4.8 \%$ \\
\hline Total (n) & 732 & 208 \\
\hline
\end{tabular}

$* \mathrm{p}<0.05-* * \mathrm{p}<0.01$.

When going more in detail, the distinction in the Perception category essentially comes from one specific type of failure: the 'Non-detection in a situation of limited visibility', typically more found in urban area, which is easily explainable by the prevalence of obstacles to the visibility (buildings, vehicles, signalization, etc.) in such environment. Dealing with the difference at the Prognosis level, there is also one specific failure which stands out quite particularly: the 'Expectation by default of no maneuver by another user', characterizing nearly one third of the riders' failures in urban accidents. The process of this failure is complex insofar as it combines some factors dealing with the rider himself (feeling of right of way, illusion of visibility) and the opposite road users who fail to notice the oncoming PTW. Finally, the bigger representation of PTW riders' execution failures found in non-urban crashes essentially corresponds to the 'Poor controllability of the vehicle when faced with an external disturbance', such as a tight bend, a wet road, etc., leading the riders to lose the control of their machine.

Such differences attest that, through the layout design and the traffic interactions supported, the environment has an incidence on the difficulties met by PTW riders on the road and the resulting human failures to which there are subject. 


\subsection{Car driver failures when confronted with a PTW}

Most PTW traffic crashes involve a passenger car. So it is important to understand also the kind of difficulties met by car drivers when encountering a PTW. Such an analysis makes it clear that car drivers are particularly prone to perception failures as regard as PTWs (Table 3 ) and even a little bit more when the crash occurs in an urban area $(64.3 \%$ vs. $58.4 \%)$ due to the numerous potential obstacles to visibility, whereas fixed or moving. Even if this last difference is not statistically significant, the huge amount of perceptive problems contributing to crashes attests the potential of urban development, notably, in preventing such crashes.

Table 3: Distribution of car drivers' failures when meeting a PTW in urban and countryside crashes.

\begin{tabular}{|l|l|c|}
\hline & Urban & Non-urban \\
\hline Perception & $64.3 \%$ & $58.4 \%$ \\
\hline Diagnosis & $5.8 \%$ & $14.4 \% *$ \\
\hline Prognosis & $10.5 \%$ & $9.6 \%$ \\
\hline Decision & $17.0 \%$ & $11.2 \%$ \\
\hline Execution & $1.4 \%$ & $4.8 \%$ \\
\hline Generalized & $0.9 \%$ & $1.6 \%$ \\
\hline Total $(\mathrm{n})$ & 569 & 125 \\
$* \mathrm{p}<0.05$ & &
\end{tabular}

The perception problems involved in crashes confronting a car driver to a PTW have given rise to previous studies, relying notably on in-depth accident analysis, the results of which could lead to specific adjustments of urban design and traffic regulation. Among such developments can be promoted the treatment of obstacles to visibility, the suppression of useless sources of distraction (e.g. advertisements) and complicated infrastructure, but also traffic calming measures as far as the speed of motorcycles has been proved to have an effect on their detectability [14].

\subsection{Riders failures in town according to the type of PTW}

If we now concentrate on urban accidents, a question remains to whether the different types of PTW encounter the same difficulties in the traffic or if there is a specificity of the safety problems met by some of them. As expressed on Table 4, a first particularity comes from the Moped category which shows significantly more riders primary contributing to their accident (42.6\%) than the two other categories that are Light motorcycles and Heavy motorcycles (respectively $27.2 \%$ and $28.4 \%$ ). These two last types of PTW are far more concerned by a secondary contribution to the non-resolution of the conflict generated by another road user, who is most of the time a car driver. 
Table 4: Riders' level of involvement for different types of PTWs.

\begin{tabular}{|l|l|l|l|}
\hline & Moped & Light motorcycle & $\begin{array}{c}\text { Heavy } \\
\text { motorcycle }\end{array}$ \\
\hline Primary contributing & $42.6 \% * *$ & $27.2 \%$ & $28.4 \%$ \\
\hline Secondary contributing & $50.3 \%$ & $65.3 \% * *$ & $59.6 \% *$ \\
\hline No contributing & $7.2 \%$ & $7.5 \%$ & $12.0 \% *$ \\
\hline Total $(\mathrm{n})$ & 390 & 173 & 225 \\
\hline
\end{tabular}

$* \mathrm{p}<.05-* * \mathrm{p}<.01$

Another difference between types of PTWs concerns crashes that occurred in urban areas, which addresses the question of human functional failures, Table 5. Mopeds once again differentiate from the others by showing significantly more failures in Perception (31.8\% of their failures) and Decision (11.4\%). Motorcycles, whether Light or Heavy, are far more subject to Prognosis failures $(52.2 \%$ and $45.8 \%)$.

Table 5: Distribution of riders' failure categories for different types of PTWs.

\begin{tabular}{|l|c|c|c|}
\hline & Moped & Light motorcycle & Heavy motorcycle \\
\hline Perception & $31.8 \% * *$ & $24.5 \%$ & $21.4 \%$ \\
\hline Diagnosis & $11.4 \%$ & $6.9 \%$ & $9.5 \%$ \\
\hline Prognosis & $29.1 \%$ & $52.2 \% * *$ & $45.8 \% * *$ \\
\hline Decision & $11.4 \% *$ & $4.4 \%$ & $5.5 \%$ \\
\hline Execution & $12.0 \%$ & $9.4 \%$ & $16.9 \% *$ \\
\hline Generalized & $4.3 \%$ & $2.5 \%$ & $1.0 \%$ \\
\hline Total $(\mathrm{n})$ & 368 & 159 & 201 \\
\hline$* \mathrm{p}<0.05-* * \mathrm{p}<0.01$ &
\end{tabular}

One explanation of the differences between mopeds and the other kinds of PTWs refers to the age of the riders. As shown in Table 6, the distribution of riders' age in the sample is not identical for the different categories of PTWs, moped riders being significantly younger than the other riders. Such a difference can account for example for the wrong decisions taken by moped riders notably regarding risky maneuvers undertaken. The relative lack of experience characterizing the youngest can also explain their weakness regarding perception, in relation with to a lower ability to develop efficient information gathering patterns. On the opposite, an important level of experience may have the side effect to promote a too strong trustfulness of the riders in their own anticipations, relying notably on a too strong feeling of right of way [15]. Such questions should be further investigated to better qualify these differences.

Table 6: Distribution of riders' age for different types of PTWs.

\begin{tabular}{|c|c|c|c|}
\hline & Moped & $\begin{array}{c}\text { Light } \\
\text { motorcycle }\end{array}$ & $\begin{array}{c}\text { Heavy } \\
\text { motorcycle }\end{array}$ \\
\hline Age mean (standard deviation) & $23.3(10.4)$ & $34.9(10.7)$ & $34.3(10.5)$ \\
\hline
\end{tabular}




\subsection{Most typical PTW accident configurations found in town}

Typical accident configurations have the interest to present in a synthesized way the major mechanisms extracted from a case by case analysis. They are built on the basis of an overall similarity regarding the chain of events, malfunctions and causal relationships. The identification of the most frequent typical accident configurations gives an immediate indication on the problems to solve, notably through road design and traffic policy [16].

Three major typical accident configurations characterize the safety problems met by PTWs inside the urban traffic, representing together more than $20 \%$ of the accident sample. They are summarized hereafter. More detailed information on PTW crash scenarios can be found in [15] and [16].

\subsubsection{Configuration B.1.3: a PTW rider overtakes a car turning across}

The PTW circulates behind a passenger car which slows down with or without its indicator. The PTW rider decides to overtake the car, either that he did not plan the maneuver, or that he is convinced to have been seen, or thinks he will master the situation if it is not the case. At the same moment, the passenger car makes a change of direction in intersection or in private access, on the trajectory of the PTW, Figure 1.

\subsubsection{Configuration B.1.1: a car driver turns across an oncoming PTW}

The PTW circulates on a priority axis. A car driver, arriving in the opposite way and wishing to turn across the road, does not detect the PTW in spite of no hindered visibility. The rider, persuaded to be seen and confident in his priority feeling keeps his momentum. The car driver engages his change of direction and cuts in front of the PTW rider who has no more the possibility of making anything to avoid the crash, Figure 1.

\subsubsection{Configuration A.1.7: a PTW filtering versus a car crossing the road}

A PTW rider is filtering (overtaking) along a line of vehicles going slow. A vehicle of the line stops or slows down to allow a non-priority coming car to pass of him (private road, car park or intersection). The car driver starts to cross the road and do not detect the PTW masked by the line of vehicles. In the same way, the PTW rider does not detect the car crossing also masked by the line, Figure 1.

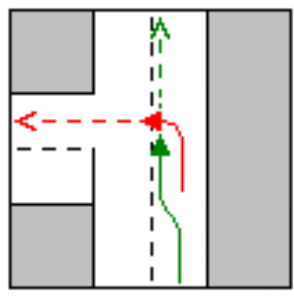

B.1.3

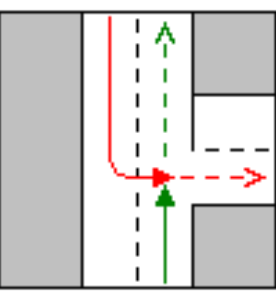

B.1.1

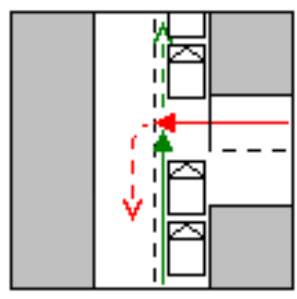

A.1.7

Figure 1: Main typical PTW urban accident configurations. 
These three main typical configurations well illustrate an important stake in PTW road safety and even more particularly in urban traffic. They present the particularity to all involve contradictory movements of a PTW and a passenger car occurring at an intersection which leads them to an antagonistic path, ending into a conflict; reminding that the victim of this conflict is nearly systematically the PTW rider. The human failures that can be inferred from the in-depth case by case analysis stresses the importance of an efficient reciprocal perception, understanding and anticipation between road users in their interactions. Of course, the road infrastructure cannot be viewed as a systematic and direct cause of these human failures. But road design plays at least an indirect role on the complexity of the task devoted to the different road users, through the movements induced or permitted, through the visibility offered, through the quantity of information to integrate, etc. By such, adapting this road design in a way to integrate human frailty constitutes an essential lever of road safety. This involves first the prevention of human error with the development of road users' friendly roads, e.g. traffic calming, efficient use of roundabouts, simplified situations, etc. This encompasses of course also the protection of these road users against injury in case of a failure in their attempt to adapt to traffic situations, e.g. suppression of aggressive obstacles.

\section{Conclusion}

Every system conceived and dedicated to a human usage must be elaborated in a way to conform to human characteristics, in a way to make an efficient use of their qualities without exceeding their limits and taking into account their eventual weaknesses. It is a founding principle of ergonomics that can be applied to the traffic domain. Road environment is both a physical medium that ensures mobility and the background for understanding the events that occur while driving. The way in which it is adapted to its users has a considerable influence on their behaviour, especially in urban areas where design is over determinant.

Urban management policies have changed over the past twenty years and now attempt to take into account and satisfy numerous concerns (safety, quality of life, etc.). However, both the number and severity of urban traffic accidents remain high. A particular trend to this regard is the growing inscription of powered two wheelers in the urban traffic those last decades. Along this evolution, PTWs have now become an integrated part of the traffic system offering certain benefits over other modes of transport, notably dealing with traffic congestion. By such, the specificities of PTWs must be integrated in the considerations underlying traffic programs and policies, especially when road safety is concerned. A good knowledge of the mechanisms of PTW involvement in injury traffic accidents should allow a significant improvement in their safety through adapted urban road development and traffic policy 


\section{References}

[1] Lévy-Leboyer, C., Psychology and environment, Sage Publications: New York, 1982.

[2] Casner, S. M., Understanding the determinants of problem-solving behavior in a complex environment. Human Factors, 36(4), pp. 580-596, 1994.

[3] Fleury, D., Sécurité et urbanisme; la prise en compte de la sécurité routière dans l'aménagement urbain, Presses de l'ENPC: Paris, 1998.

[4] Van Elslande, P. \& Fouquet, K., L'erreur urbaine: défaillances, facteurs et contextes de production des accidents d'agglomération, Collections de l'Inrets: Arcueil, 2005.

[5] Ducreux, B. O., Powered Two Wheelers compared with cars: Driving dynamics, fuel consumption and exhaust emissions in daily use. Ademe: Vabonne, 2008.

[6] Rogers, N., Trends in Motorcycles Fleet Worldwide, http://www.internationaltransportforum.org/.

[7] Van Elslande, P. \& Elvik, R., Powered two-wheelers within the traffic system. Accident Analysis and Prevention, 49, pp. 1-4, 2012.

[8] Elvik, R., Benefits and fairness: are the high risks faced by motorcyclists fair? (Chapter 1). Les deux-roues motorisés: nouvelles connaissances et besoins de recherche, ed. P. Van Elslande, Les collections de l'Inrets: Bron, pp. 17-26, 2009.

[9] DACOTA, Traffic safety Basic Fact 2010: Motorcycles and Mopeds, $\mathrm{http} / / / \mathrm{www}$.dacota-project.eu/index.html.

[10] OECD. Road accidents: on-site investigations, Road Transport Research programme, OECD: Paris, 1988.

[11] Van Elslande, P., Naing, C. \& Engel. R., Analyzing human factors in road accidents. TRACE European Project, Deliverable 5.5, www.traceproject.org.

[12] Van Elslande, P. Fournier, J.-Y. \& Jaffard M., Influence of Cannabis on Fatal Traffic Crash: A Detailed Analysis. Transportation Research Record, 2281, pp. 43-50, 2012.

[13] Landis, J. R. \& Koch, G. G., The measurement of observer agreement for categorical data. Biometrics, 33(1), pp. 159-174, 1977.

[14] Brenac, T., Clabaux, N., Perrin, C. \& Van Elslande, P., Motorcyclist conspicuity-related accidents in urban areas: a speed problem? Advances in Transportation Studies, 8, pp. 23-29, 2005.

[15] Jaffard, M. \& Van Elslande, P., Typical human errors in traffic accidents involving powered two-wheelers. Advances in Traffic Psychology, ed. M. Sullman \& L. Dorn, International Association for Analytical Psychology: Ashgate, pp. 95-104, 2012.

[16] Clabaux, N., Prevention of traffic accidents involving powered twowheelers in urban areas: prototypical accident scenarios and prospects for the planning and design of the urban road infrastructures. Proc. of the European Transport Conference 2007, Leeuwenhorst, 2007. 